Journal of Jazz Studies vol. 8, no. 2, pp. 163-173 (Winter 2012)

\title{
Jazz Studies: Mainstream or Listing in a Sea of Ideology?
}

\author{
Randall Sandke
}

In the previous edition of the Journal of Jazz Studies, scholar Andrew Sanchirico contributed an article entitled "Is Conventional Jazz History Distorted by Myths?" In it, he takes me to task for stating in my book, Where the Dark and Light Folks Meet, that historical inaccuracies in the form of myths are still being taught on college campuses throughout the country.

Sanchirico and I seem to be in agreement that those portions of jazz historiography I identify as myths are indeed inaccurate representations of the historical record. But he feels that, in general, such facts are well known and widely accepted by jazz scholars today, whose work is more professional ("scholarly and dispassionate" in his words) than that of previous generations of amateur jazz historians.

To support his claim, Sanchirico cites fourteen jazz histories, twelve of which I fail to mention in my book, and determines that these books are largely free of the inaccuracies I criticize. He feels I was remiss in not consulting these books, which to him represent the "mainstream" of current jazz scholarship as taught today. He concludes that, "the perpetuation of jazz mythology among recent jazz historians is far less prevalent than Sandke would have us believe," and my failure to acknowledge this development reveals "a fundamental weakness underlying Sandke's treatment of jazz mythology."

First, I'd like to thank Dr. Sanchirico for taking the time to write a thoughtful and scholarly paper concerning my book. He raises important and substantive issues, which merit further discussion, and I appreciate the fact that his article has provided me an opportunity to do just that.

I will go into Sanchirico's arguments in some detail further on, but first I'd like to begin with some general comments. Now that nearly three years have passed since my book was released, I've had time to reflect on its critical reception, both good and bad, and how I might modify certain passages if a new edition were ever prepared.

The book had its genesis in my perception that politics (and specifically racial politics) was intruding into the creative energy and further development of the music itself, particularly in the 1980s and '90s. Some critics and writers 
of the time complained of the lack of risk-taking and innovation of that era, though their calls went largely unheeded (and I've been taken to task for not mentioning their efforts in my book as well). To my mind, the more music becomes politicized, the more it becomes de-musicalized.

I felt that these developments were stifling creativity for both black and white musicians. Both were encouraged to "celebrate the tradition" and eschew musical exploration; and of course, white musicians didn't fit comfortably into the "jazz as cultural icon of black achievement" vision that became so commonplace at the time.

The more I investigated racial interaction (which is the principle theme of my book), the more I found the subject largely absent from most jazz texts. Dr. Sanchirico would probably point out that all jazz books deal with this topic in some way or other, but no book was exclusively devoted to it-- at least not in a comprehensive way, in terms of musicians, audiences, business interests, and society as a whole. This is the story my book attempted to tell.

As I studied the issue of interracial contact in jazz, the more I was obliged to ask myself: why was this topic so frequently misunderstood and misrepresented? Why was so much mythology overlaying it? Why had it been politicized to the point where a smokescreen seemed to conceal its true nature? Was the interracial aspect of jazz characterized by cooperation and mutual benefit, or exploitation and cultural colonization?

All of this is very sensitive and controversial territory, and I was totally sincere when I stated in my book that I wish someone else had taken on this daunting task. I knew my book would draw fire, and it certainly did.

In order to define these issues I adopted the term "exclusionary" to describe the view that jazz is mainly the product of an African American sensibility and cultural environment (isolated through the malicious exercise of segregation and discrimination), and "inclusionary" for the position that it had always been open to many outside influences. In my first drafts I had used the word "separatist" instead of "exclusionary," though now I feel all these terms have unfortunate connotations. As one critic correctly pointed out, it is insensitive to use the term "exclusionary" when black people have been excluded for so long from the mainstream of American society. Were I to revise this passage, I would substitute the more race-neutral terms "monocultural" and "cross-cultural."

Words matter, and when Sanchirico claims, as he does in the abstract for his article, that my book posits that "standard jazz texts exaggerate the importance of African American culture in the development of jazz," I wince. I tried to be very careful throughout my text to stress the prime importance of African American culture in the formation and development of jazz, but 
perhaps I wasn't insistent or clear enough. What I did say, for instance, was that "much of what we consider 'black culture' is richly heterodox, and that the greatest exponents of jazz were curious and wide-ranging individuals who sought training and inspiration from a wide variety of sources" (p.87). I don't see this situation as a zero-sum-game, whereby one group's gain is another's loss. In other words, it doesn't diminish the accomplishments of black musicians to acknowledge how worldly and sophisticated many of them were; or that white musicians devoted themselves to jazz very early in the music's history. As I state in the book, it's not incorrect to say that jazz is black music, just incomplete.

Mixed in with Dr. Sanchirico's objections to my book is something I take to be very good news. I welcome the fact that the prevalence of jazz mythology is subsiding in the academic world. The more jazz frees itself from ideological dogma the better as far as I'm concerned. A truer picture of its history will undoubtedly emerge.

I am also pleased to report that the era of conformity to past glories is receding in the musical sphere. The new millennium has seen the rise of such creative and individual artists as Vijay Iyer, Brad Mehldau, Jason Moran, Scott Robinson, and Ambrose Akinmusire. Whether their work rises to the level of innovation, in terms of making a substantially new contribution to the language of jazz, remains to be determined.

While on the subject of innovation, I'd like to amplify some other comments I made in my book. As I said above, I was growing distressed that the very idea of innovation and its significance were being attacked, most prominently by people associated with Jazz at Lincoln Center (Stanley Crouch, Tom Piazza, and Wynton Marsalis, with many in the press following their lead). I didn't mean to imply that musicians should be discouraged from dedicating themselves to whatever style they love best. I have learned over the years that some musicians (Red Allen, Ruby Braff, Kenny Davern, and JonErik Kellso come immediately to mind) can be quite creative and personal in expressing themselves through older established styles. But innovation is a special case, I feel, and one that requires special care on the part of critics and writers. There is no built-in audience for new styles, and therefore little profit to be gleaned, at least initially. That's why it's vital for those in the critical community to keep an open mind and support innovation wherever they can. The promotion of ideology opposed to new ideas was an unprecedented 
development in the jazz world of the '80s and '90s, and this line of argument was irresponsible and destructive in my view. ${ }^{1}$

Now let's return to Dr. Sanchirico's article. His fundamental argument is that the teaching of jazz, as revealed through jazz history textbooks used over the past twenty years, is nearly free of the mythology I object to in my book. But how can one know for sure? Once the classroom door is closed, a professor can have great latitude in how class is conducted.

Some teachers use texts and others don't, or may use ones of their own devising. And even if a professor bases his course on one of the books from Dr. Sanchirico's list, it's not necessarily adhered to in class. Older teachers, who formed opinions from out-dated sources, may still promote mythologies of the past. In addition, supplemental reading may include such politically laden books as Leroi Jones's Blues People, or Frank Kofsky's Black Nationalism and the Revolution in Music (which is fine as long as students understand their connection to a particular era in our history, and are alerted to the authors' biases.)

Dr. Sanchirico's list of "all surveys of jazz history published since 1990" is also incomplete and somewhat misleading. It doesn't include, for example, Brian Harker's Jazz: An American Journey (published by Pearson in 2004), nor Thomas E. Larson's History and Tradition of Jazz; Richard J. Lawn's Experiencing Jazz; Tanner and Gerow's A Study in Jazz; Allan Lowe's That Devilin' Tune: A Jazz History, 1900-1950; John Edward Hasse's Jazz: The First Century; John F. Szwed's Jazz 101; and there are others. What's significant here is that a recent review of market share showed Harker, Larson, Lawn, and Tanner among the top ten sellers of all jazz textbooks. (Mark C. Gridley's Jazz Styles and Concise Guide to Jazz; and Deveaux and Giddins' Jazz topped the list).

Of those books I've had a chance to look at, most are excellent and largely free of the extra-musical claptrap I criticize. Gridley, for instance, scrupulously avoids social issues, and focuses instead on developing listening skills and fostering familiarity with the various jazz styles strictly as musical entities. Harker, on the other hand, perpetuates the myth that Congo Square was still active into the 1880s; divides his discussion of swing era big bands along strict racial lines; and maintains that free jazz sprang from civil rights militancy in the 1960s. Tanner excerpts a paragraph from Blues People explaining how black codes in New Orleans led to a melding of Creole and African American cultures that produced jazz.

\footnotetext{
${ }^{1}$ To be sure, new and emerging styles had faced rejection before, but dedicated champions of the new music consistently managed to turn the tide.
} 
This raises another aspect of jazz pedagogy absent from Dr. Sanchirico's calculations. In his concluding remarks, one sentence struck me in particular: his claim that jazz historians of today "are writing during a time of relatively little left-liberal activism," and therefore take a more "scholarly and dispassionate approach to jazz history than the earlier generation." This latter sentiment may indeed apply to the writers of the fourteen books (several of whom I know personally) he cites, but how well does it apply to the teaching of jazz in general throughout academia?

I would argue that colleges and universities are much more politicized now than they were even in the thirties when jazz scholarship began. ${ }^{2}$ As the English historian Paul Johnson points out in his voluminous History of the American People:

"The growth of political indoctrination and malign race-theory was part of a phenomenon known as 'Political Correctness,' which swept the American campus in the 1980s and early 1990s, rather as protest swept it in the 1960s. As in the Sixties, some escaped the disease, others were heavily infected, and some succumbed. The worst aspect of PC, critics complained, was not its foolishness but its intolerance, and its tendency to stifle free speech." ${ }^{3}$

How do such trends affect the teaching of jazz? Perhaps not much. But as one professor recently told me, there is a palpable fear on the part of many teachers that something they say may be taken out of context, publicized on campus, and blown up into a scandal. This scenario would suggest that professors tiptoe around controversial issues. But it is equally true that some positions on controversial issues are more acceptable than others, i.e., more politically correct.

Here we have to look the elephant in the room in the eye. Jazz is taught most often as a music course, but it can also fulfill requirements in diversity studies. Sometimes a jazz course can be cross-listed in various departments, or be taught out of cultural studies departments, and most typically black studies. In this wing of academia, the black liberation struggle may well become the focal point of jazz history.

Out of this milieu has emerged an Afro-centric approach to jazz. Once again, some professors create their own textbooks, such as Karlton Hester of UC Santa Cruz, or use none, like Leonard Brown of Northeastern University. The title of Hester's 4-volume textbook is From Africa to Afrocentric Innovations

${ }^{2}$ In the U.S., Canada, and much of Europe that is. Of course in Nazi Germany, Hitler found strong support from both professors and students alike.

${ }^{3}$ Johnson, Paul. A History of the American People. New York: HarperCollins, 1997. 959. 
Some Call "Jazz." He has also written a book called The Melodic and Polyrhythmic Development of John Coltrane's Spontaneous Compositions in a Racist Society. Brown has published John Coltrane and Black America's Quest for Freedom. I admit I haven't read these particular books so I can't judge whether they perpetuate myths or not. But I think their titles tell us something about the authors' perspective on jazz history.

At Harvard, Ingrid Monson, the Quincy Jones Professor of AfricanAmerican music, offers a course taught out of the African-American Studies Department entitled, "Jazz, Freedom and Culture." In it she explores, among other things, how jazz "provided an arena in which complex debates about race, cultural ownership, and social disparity repeatedly took place. Understanding of the process of improvisation is paramount, as the freedom of musical expression in jazz is contrasted with the lack of freedom provided by the social and legal contexts in which the music developed."

I should make it clear that I have no overriding objection to jazz being taught from an African American perspective. As I freely acknowledge in my book, jazz was created by blacks and the vast majority of its greatest exponents have been African American. I also feel strongly that every college student in America should be well versed in African American history, simply because it's such a defining element of American history overall. My sole concern is that jazz history is presented accurately, as completely as possible, and free of bias. But it would be a mistake to assume that politics is uniformly absent from the classroom.

The following comments from an internet posting of evaluations in which students are invited to "rate your professor" make it clear that, at least in the minds of some participants, the teaching of jazz can be tinged with racial politics by a professor harboring an extra-musical agenda: "If you are white you're [sic] chances of getting above a $\mathrm{C}$ are slim. He's very boring and super pro-black." Other students spoke in a similar vein. But from one who apparently shared the professor's point of view, "this was a great class, and this is a really knowledgable [sic] man." How these statements relate to the professor's actual conduct in class is an open question, and I hazard to make judgments based on personal accounts alone. Nevertheless, there is a wealth of evidence, from course listings, student evaluations, professors' statements, and published papers and books, suggesting that the politics of racial grievance is an important element in the teaching of jazz for some professors. (And once more to clarify: plenty of legitimate grievances concerning discrimination against blacks in America certainly exist, but the question is do they take on a mythic status of their own and distort a more balanced and accurate evaluation of the growth and development of the music?) 
Perhaps this branch of jazz studies represents one end of the academic spectrum, and the majority of texts Dr. Sanchirico cites are at the other end. I'm willing to grant that most jazz history instructors (many of whom are adjuncts and/or professional jazz musicians in search of regular employment) approach the subject from a love of music rather than a desire to inculcate students with their political beliefs. But we can't pretend that a radical wing of academia doesn't exist. What Dr. Sanchirico presents in his article is one yardstick we may use to determine how jazz is taught today. But his approach is rather like sticking a yardstick in the middle of a lake (or sea) to measure its depth. This metric can only take us so far and no further. These waters run deep, and contain many countervailing currents.

Dr. Sanchirico admits to the limitations of his survey when he says (p. 79): "Sandke locates the perpetuation of jazz mythology in sources that extend far wider than the writers and books included in this study. In particular, he is especially critical of college professors who he accuses of using their courses to advocate an exclusionary viewpoint and to perpetuate jazz mythology. It could therefore be argued that the present study has ignored precisely those sources that are most responsible for the perpetuation of jazz myths."

Let's return to some specifics of Dr. Sanchirico's evaluation of my book. The first myth I explore, and the first that Sanchirico discusses, has to do with the African origins of jazz. Sanchirico writes that, "It is Sandke's contention that jazz writers have greatly exaggerated the African influence, leading to the widespread and erroneous belief that jazz has African origins and is an extension of traditional African music." This is not an entirely accurate summation of my position, in that I never question the ultimate African basis for jazz. Rather, the question I pose is: "Is jazz related to African music the way English is related to Indo-European; that is, as one of many offshoots that have evolved into separate and discrete languages" (p.39). As evidence of the latter proposition I state that, "the use of polyrhythms is frequently mentioned [in jazz texts], but not the totally different way polyrhythms function in African music" (p.40). I then attempt to describe this difference in musical terms. If I were to write a headline for my argument, it would be: Use of African and Jazz Polyrhythms Not the Same! I admit that I have not read all the fourteen books on Dr. Sanchirico's list, but I'd be surprised if any stress this point as I have done.

The second myth concerns the role, if any, Congo Square played in the formation of jazz. Sanchirico concludes that "there is relatively little agreement" on this issue in the books he cites. "Five of the recent books make no mention of Congo Square whatsoever." Nevertheless, "the recent writers make one thing clear: the Congo Square events were discontinued too soon to 
have had a direct impact on the creation of jazz." All that is well and good. But whatever these books say or don't say, I would contend that their approach to Congo Square is very different from mine. I am attempting to put a stake through the heart of this myth once and for all. Again, I think my position, and aim, regarding this issue is fundamentally different from other books.

The idea that Jim Crow laws had a decisive role in the creation of jazz is the one myth that Sanchirico still finds in most of the books he looked at. Thankfully, he acknowledges the inaccuracies engendered by this assessment, and notes that only two books are "neutral" (meaning they don't mention the issue at all). I would only add that my research on the subject largely rested on that of Louisiana historian Jerah Johnson. In order to gauge the current political climate infecting academic debate, consider the fact that Johnson's essay on Jim Crow laws and jazz, which is a marvel of thorough and original research, was rejected by American academic publications, and only found an outlet in England. I would also note that Mark Gridley has expunged any reference to this issue from the latest edition of Jazz Styles as a result of reading my book.

Another section of my book that Sanchirico examines is entitled "Buddy Bolden: Separating Fact from Fiction.” He points out that, since the 1978 publication of Donald Marquis' landmark book In Search of Buddy Bolden, previous myths concerning the cornetist's life have been dispelled, and Marquis' findings have become universally accepted by jazz scholars. Perhaps. But again, it's a question of emphasis. Though it may be widely acknowledged that Bolden grew up and lived in "an integrated workingman's neighborhood where every kind of music was his for the hearing" (as told in Ward and Burns, p.21), my book notes that Bolden: lived two doors down from the white Shields family, which included the future clarinetist of the Original Dixieland Jazz Band; had close Creole connections; may have participated in school productions of Gilbert and Sullivan operettas; came from a family listed as being of mixed race in the 1870 census; and was probably not the first instrumental blues performer, just the most popular and best known of his time. I would contend that these details paint a very different picture than the one in, say, Burton J. Peretti's Jazz in American Culture, which states only that, "the first known jazz cornetist, Charles 'Buddy' Bolden, was from a 'holy roller' Protestant family from the Delta" (p.21). (This despite the fact that, according to Marquis, Bolden's grandfather was born somewhere in Louisiana, and his grandmother came from [or was transported as a slave through] Virginia. The family remained in New Orleans from then on. Where Peretti gets his information is unknown because the book contains no footnotes.) 
Next we come to a myth that Sanchirico headlines: Rhythm Was the Defining Characteristic of Bebop. This concept was advanced in Martin Williams' book The Jazz Tradition, a text I cite, and one of Sanchirico's fourteen. However, I would state the bullet point of my argument somewhat differently: black musicians invented bebop while attempting to come to terms with the harmonic implications of sophisticated American pop tunes of the 1930s composed by Gershwin, Porter, Berlin, et al. This is a view that is not explicitly expressed in any jazz text I am aware of, not even Scott DeVeaux's The Birth of Bebop.

Likewise, the association between black avant-garde music and the Western modernist tradition is evaluated by Sanchirico. He determines that thirteen of the fourteen books he examined speak to this connection. I'm willing to concede his point. But again, I feel that a section in my book devoted to this issue was warranted given the fact it is typically overwhelmed by discussions of rising black political consciousness.

The final myth Sanchirico discusses has to do with the preponderance of white audiences throughout the history of jazz. He protests that I offer no evidence of writers ignoring this phenomenon, and almost every book he lists contains some account of black musicians performing for white audiences. That may be, but I was attempting to present a far more comprehensive view: I wasn't merely noting that blacks playing for whites was commonplace, but that "all the major jazz figures-including Louis Armstrong, Duke Ellington, Billie Holiday, Charlie Parker, and Miles Davis—spent the bulk of their careers playing for white audiences" (p.139). Many probably wouldn't have had significant careers at all if not for the support of white audiences. I doubt that any of the fourteen books on Sanchirico's list state this fact so plainly and explicitly. Peretti, for example writes that, "Few white listeners found the 'hot' styles of Armstrong or Ellington to their taste" (p.57). Again, such a statement may be technically correct, if, for example, one means that a small percentage of the white population listened to their music. Nevertheless, it was white audiences, both in the US and abroad, that kept these artists, and so many others, in business.

This chapter in my book, entitled "The Biggest Myth of All," is in effect a full history of jazz from the standpoint of the audience, starting from pre-jazz Colonial times and going up to the present. If any other book tells this story in as much detail as I do, I'm not aware of it. In the process of relating my account, I touch on many other issues fraught with mistaken conventional wisdom or faulty scholarship, such as: rather than being discriminated against in the marketplace, black bands providing syncopated dance music were favored by upper-crust white society all the way from the 1890s through the 
'teens, and even into the '20s; the reason for the loss of this privileged position was a growing market for bands that could play in both "sweet" and "hot" styles, and black bands were discouraged from abandoning their jazz niche; the flourishing Kansas City jazz scene before the Second World War did not cater to primarily black audiences, as many jazz texts imply, but followed the model of the black-and-tans of the '20s; and that Bebop and the Avant-Garde, unlike the picture that Peretti and others paint, flourished overwhelmingly in interracial settings. This chapter, over the course of 28 pages, reveals the close, mutually beneficial, and financially as well as artistically rewarding relationship existing for over a hundred years between black jazz musicians and white audiences. It is a perspective that, if mentioned in other books, never seems to get the acknowledgement it so richly deserves.

Although Dr. Sanchirico examines only two chapters in my book, the entire text is really concerned with debunking myths. Others include: whether there was a pro-emancipation aspect to minstrelsy; was there a significant white presence in the early New Orleans jazz scene from the end of the $19^{\text {th }}$ Century to the First World War? Were many black musicians, even in early days, classical trained? Were there significant white jazz stylists of the '20s who had no apparent black mentors or role models? (The answer to all of the above is yes.) Then there are the business aspects of jazz: were blacks systematically shut out of the recording business? Did they receive less pay? Why were they typically excluded from studio bands? To what extent was the relationship between black musicians and white management exploitative? Again, if there are other books that deal with these issues in as much detail as I do, I'm not aware of any.

One of the points I wanted to make in my book is that all of this mythology is connected, in that it attempts to depict black culture as essentially isolated and dependent on its own resources, i.e. largely impervious to outside influences. The corollary to this view is that white involvement in jazz has been largely predatory to the extent it's been involved at all. It is my belief that such a position begs far more historical questions than it answers.

I must underline the fact that none of my conclusions discount or ignore the appalling reality of racism and discrimination facing African Americans throughout the bulk of American history. But jazz was most often seen and experienced as a bridge across the fault line between the races rather than an expression of its depths. Most whites, perhaps nearly all, who appreciated and supported jazz, were eager to foster interracial respect and understanding. Duke Ellington, for one, did his part to encourage universal (or, if you will, cross-cultural) brotherhood by telling his audiences around the world, "We love you madly!" 
I'd like to thank Dr. Sanchirico again for offering me a chance to respond to his article, which, as I said earlier, raises important and valid points. No historian gets everything right, and I'd be the first to admit that my book is far from perfect. Whatever its defects, one of my main intentions in writing it was to help initiate a new and frank dialogue on jazz and race. This subject has been the elephant in the room for too long; one that must be approached gingerly, and according to an increasingly formalized ritual of political correctness fraught with showy displays of outrage at the racist world we live in. Let there be no doubt that I would much prefer this situation over a return to legally sanctioned segregation and a conventional wisdom dictating that some races are superior to others. But are these the only choices we have? I think not. And scholars are the ones who should perceive the subtleties and inconsistencies in history and human nature better than most.

\section{ABOUT THE CONTRIBUTOR}

RANDALL SANDKE has been a professional jazz musician for the past thirty years and has appeared on numerous recordings, most recently Scott Robinson's Bronze Nemesis. In addition to Where the Dark and the Light Folks Meet (Scarecrow Press, 2010), he is the author of Harmony for a New Millennium published by Hal Leonard Music. 